\title{
Default and Abandonment Option in Motorway Concessions
}

\author{
Fernando Cabero Colín, Antonio Sánchez Soliño and Antonio L. Lara Galera
}

\begin{abstract}
As long as motorway concessions are subject to the variability of traffic demand, it is necessary to apply valuation methods that can take into account that uncertainty. In the past, many concession projects have faced an early termination of the contract due to lower traffic than expected. These insolvency situations raise the issue of the compensation to the concessionaire when the contract is prematurely terminated. A methodology based on the real-options approach has been developed in this paper to assess insolvency situations in motorway concessions. Under this approach, the mechanism of compensation can be modeled as an abandonment option, granted by the public administration to the concessionaire, in which the value of the option will depend on the evolution of traffic. This methodology is then applied to the case of a real concession in Spain. The results show a significant value of the abandonment option, which represents an implicit aid from the public administration to the concession. In this way, the methodology presented in this paper can contribute to gaining a better understanding of the risks of motorway concessions and enhancing the transparency in concession contracts.
\end{abstract}

Author keywords: Real option; Guarantee; Uncertainty; Motorway; Concession; Default.

\section{Introduction}

In the field of transportation infrastructure, investment projects have some specific features that are different from other types of investment. In general, infrastructure transportation projects have a high degree of uncertainty, require an important amount of resources, and are, to a large extent, irreversible. These features are clear in motorway concessions, where there is a wide potential for the application of the real-options approach. The latter is particularly appropriate in the context of strategic decision-making process and in the evaluation of investment opportunities under conditions of uncertainty. The use of traditional methods of investment appraisal, based on discounted cash flow, is inappropriate in valuing projects that involve managerial flexibility. When the discounted cash-flow method is used to value a project, the real options attached in it are implicitly ignored. It means that discounted cash-flow methods do not reflect the value of management (Brealey et al. 2010).

The traditional discounted cash-flow approach assumes a single-decision pathway with fixed incomes and outcomes, and all decisions are made at the beginning of the project, or in the tender process, without the possibility to change and develop them over time. The real-options approach takes into account a wide variety of decision pathways as a consequence of the high uncertainty involved in projects, coupled with management's flexibility

\footnotetext{
${ }^{1}$ Researcher, Polytechnic Univ. of Madrid, c/ Santa Engracia 101, $2^{\circ} \mathrm{C}$, 28010 Madrid, Spain. E-mail: fcabco@gmail.com

${ }^{2}$ Associate Professor, Polytechnic Univ. of Madrid, ETS Ingenieros de Caminos, c/Profesor Aranguren s/n, 28040 Madrid, Spain (corresponding author). E-mail: asanoli@ ciccp.es

${ }^{3}$ Associate Professor, Polytechnic Univ. of Madrid, ETS Ingenieros de Caminos, c/Profesor Aranguren s/n, 28040 Madrid, Spain. E-mail: alargal@ ciccp.es
}

in selecting the optimal strategy as soon as new information becomes available (Kester 1984; Mun 2002).

In a strict sense, the real-options method is the extension of the financial options theory to options on real assets. Financial options models use the close relationship between the underlying asset and the derivative asset (the option) to replicate the results of a riskless asset. The possibility of establishing a replicating portfolio permits the calculation of the value of any contingent financial claim, simply through observation of the capital markets. This evaluation methodology makes it possible to use the known price of an asset to estimate the relevant price of other assets whose value depends on the former.

The development of the financial derivatives theory has allowed the existence of numerous models for the valuation of different financial options, starting from the first works carried out by Black and Scholes (1973) and Merton (1973). Real options use these models, by analogy, to value the different contingent claims that are implicit in investment projects.

In the case of motorway concessions, real options arise in a natural way from the interpretation of the clauses established in the actual contracts. After all, the real-options approach contributes a valuation tool, but the terms of the options are embedded in the contracts that regulate rights and obligations for both contracting parties. Some of the existing or possible real options in motorway concessions are as follows (Lara Galera 2006):

- Minimum traffic guarantees (traffic floors) or maximum traffic limitations (traffic caps).

- Public subsidies when traffic is lower than expected.

- Investment in new motorway stretches.

- Early abandonment of the concession.

- Anticipated reversion of the concession.

- Public participation loans.

- Extension of the concession period.

These mechanisms reduce cash-flow volatility, add flexibility to the project, and allow a better management of the concession based on the occurrence of future events. Some of these mechanisms have been used one way or another in toll-motorway programs in different countries. In this paper, the case of the early abandonment of a project is studied. 
The growing experience in public-private partnerships (PPPs) for the provision of public infrastructure shows that, in a significant number of cases, the private partner reaches a situation where it is unable to meet its financial obligations.

There are examples of major contracts where the project could not be completed due to an inadequate cost control, which was the case of the Metronet PPP. This project was launched in 2002 for the modernization of the London Underground. This project was suspended, which caused the early termination of the contract and was returned to public management (National Audit Office 2009).

Nevertheless, the main source of uncertainty in the majority of infrastructure projects is the level of demand, especially in toll-road concessions (Chen and Subprasom 2007). Therefore, most PPPs insolvency situations possibly occur when the private partner's revenues depend on the demand, and it turns out to be much lower than initially expected. Some important examples include the highway program in Mexico between 1989 and 1994 (Carpintero and Gómez-Ibañez 2011) and, more recently, motorway concessions in Spain (Baeza and Vassallo 2010).

Under a concession contract, the legal ownership of the concession-related assets and the responsibility of the service correspond at all times to the public administration or the public granting authority. Therefore, throughout the bidding process, the public administration shall make sure that the concessionaire provides guarantee for both technical and financial success to meet the contract properly. Nevertheless, when a concession contract is terminated due to a situation of insolvency, the issue of compensation to the concessionaire arises. Apparently, in the case of a breach of contract by the private partner, the existence of a compensation would be questionable; in fact, an indemnity to the public administration should be considered. However, when a certain asset built by the private partner (e.g., a road) returns to the public sector due to the early termination of the contract, the absence of compensation to the private partner would cause an unfair benefit for the public administration (HM Treasury 2007).

The asset transferred to the public sector will have a certain value, which must be paid as a compensation to the private partner after subtracting the indemnity to the public administration that may correspond to the breach of its obligations. The question, therefore, is to establish the criteria for determining such compensation. In general, those criteria vary across countries. In many cases, there is no specific legislation to determine the compensation value; instead, the concession contract itself determines the value or, in some cases, the criteria to calculate it (HM Treasury 2007).

It should be taken into account that the possible compensation to the private partner in default cases is a key element considered by the financial institutions funding the projects. However, the valuation of the compensation at the time of signing the concession contract is a complex problem. This is due to the fact that it is a contingent compensation that only takes place in certain circumstances, this is, when a turn of events occurs leading the project to insolvency.

Therefore, a distinction has to be made between the determination of the compensation in case of contract termination (the value of which will be determined by law or by the concession contract itself) and the valuation of such compensation (treated as a contingent asset) at the time of signing the concession contract.

The valuation of the compensation as a contingent asset can be performed when a significant variable can be identified whose evolution over time can be adequately monitored. A methodology is presented in this paper based on the theory of real options to assess the valuation of this type of compensation. The overall idea is that the mechanism of compensation in case of default can be modeled as an abandonment option provided by the public administration to the concessionaire. In such a model, the concessionaire will decide whether or not to terminate the contract based on the evolution of the concession outcome.

At the time when the valuation of the option is made, future results of the concession are contingent. In this study, it is assumed that such results will depend fundamentally on the traffic evolution on the motorway. Therefore, the traffic becomes the underlying asset of the motorway concession. According to the stochastic process followed by traffic volume, and based on the value of certain parameters, it is possible to determine the value of the abandonment option.

A similar approach is followed by Zhao et al. (2004) for a theoretical analysis of the decision-making process in highway development. Chiara et al. (2007) assessed the value of a revenue guarantee granted by the government in a concession project. The methodology of real options has the advantage of considering a neutral environment regarding risk. This rules out the issue of determining an appropriate discount rate for the future cash flows of the project, an issue that would be practically unsolvable due to the existence of the option itself.

In this work, this methodology will be applied to the case of toll-motorway concessions in Spain. In this country, the compensation for the concessionaire is regulated by law, and is based on the investment made by the concessionaire, taking into account the amortization of such investment. Nevertheless, the methodology would be analogous for any other criteria employed to establish the compensation, although the results would logically be different in each case. In the following section, the abandonment option is characterized, as well as the methodology used for the valuation of the compensation. Then, such methodology is applied to the abandonment option arising in a real case of a motorway concession in Spain. Finally, the main conclusions of the paper are summarized.

\section{Abandonment Option in Motorway Concessions}

The classical perspective of the investment theory presents projects as irreversible until the end of their life; only at that moment the reallocation of the employed resources occurs. However, the reality shows a very different scenario. A study on the diversification of 33 large U.S. companies during the period 1950-1986 (Porter 1987) shows that most of them abandoned many more projects than they kept.

The projects incorporating some flexibility regarding the uncertain development of future events logically involve a greater value versus those who do not have this flexibility. The possibility of abandoning or liquidating a project at a given time for a higher value than expected if it continued to be operated provides this kind of flexibility and can be considered an implicit real option in the project. This option is valuable to their holders, because it enables them to recover a certain part of the investment in unfavorable situations.

The option of abandoning a project is formally equivalent to an American put option with an exercise price equal to the value of abandonment of the project. However, it is not a simple put option because the project provides some uncertain cash flows and has a value of abandonment or settlement, which may be uncertain too.

The first authors to recognize the value of abandonment in the analysis of investment projects were Robichek and Van Horne (1967). They stated that projects with significant abandonment values must incorporate the abandonment option in the capital budgeting process for optimal capital allocation within the firm. Aware of its importance, they proposed a method for analyzing the abandonment option. They considered that a project should 
be abandoned at the time when the abandonment value exceeds the present value of future cash flows.

One of the first authors to study the abandonment decision from the perspective of real options was Margrabe (1978). Subsequently, Myers and Majd (1990) devised a model based on a put option with an uncertain exercise price. The total value of a project would be given by its own cash flows plus the value of the abandonment option. When the present value of the project falls below its liquidation value, the act of abandoning or selling the project is equivalent to exercising the put option with a strike price equal to the liquidation value of the project which sets a lower limit value thereof. Therefore, a project that may be settled in this way is worth more, or equal, to a similar project without the possibility of abandonment.

In motorway concessions, real options arise out of the interpretation of the clauses of the concession contracts themselves, which regulate the rights and obligations of the concessionaire. Alternatively, such options may stem from the legislative framework that applies to such contracts.

From the perspective of the theory of options, the compensation for the concessionaire in case of default would be equivalent to the exercise price of an abandonment option implicit in the concession contracts. However, note that in other kind of projects it can be assumed that the abandonment can occur at any time. This is not possible in motorway concession contracts, due to the nature of public interest of the transportation infrastructure.

In other words, the exercise of the abandonment option (and the corresponding payment of the exercise price) will not be automatic, but will generally be preceded by negotiations between the administration, the concessionaire and, where appropriate, the financial institutions. In this case, the abandonment option (for purposes of modeling) could be envisaged, in theory, as a put option that could be exercised in a limited number of dates; for example, annually within the operating period. The optimal time to exercise the option would be an additional outcome of the modeling process itself.

Under this approach, there are different procedures to determine the value of the abandonment option. The one chosen for this work is the Monte Carlo simulation method for its simplicity, intuitiveness, and flexibility to incorporate different sources of uncertainty. The use of a simulation method to determine the value of real options in transportation networks can be found, for example, in Chow and Regan (2011).

Assume a motorway concession with an expected duration of $N$ years, in which the free cash flow generated in a given period $t$ depends on the traffic volume $\theta_{t}$ in that period, that is, $\mathrm{FCF}_{t}=f\left(\theta_{t}\right)$, where $\mathrm{FCF}_{t}$ is the free cash flow of the project in period $t$.

It should be made clear that this free cash flow refers to the concession project as such, regardless of the flow of finance between the concessionaire and the funding institutions. Therefore, the value of the abandonment option that is calculated represents the value of such option regarding the project as a whole, not only for the concessionaire.

Based on earlier studies of traffic in motorways (Sánchez Soliño and Lara Galera 2012; Cabero Colín et al. 2013) it has been considered here that the traffic evolves over time following a geometric Brownian motion with parameters $\alpha$ and $\sigma$, where $\alpha$ is the process drift and $\sigma$ its volatility. Therefore

$$
\frac{d \theta_{t}}{\theta_{t}}=\alpha d t+\sigma d z
$$

where $d z=$ Wiener process.
By analogy with financial assets, an expected rate of return $\mu$ can be defined from the asset traffic that must comply, according to the capital asset pricing model (Sharpe 1964)

$$
\mu=r+\beta\left[r_{m}-r\right]
$$

where $r$ = risk-free rate of return; $r_{m}=$ market rate of return; and $\beta=$ sensitivity factor that measures the variation of the return on assets in relation to the variation of market performance (Lara Galera 2006).

However, it is also known that, for any asset, the potential sources of returns come from capital gains and dividends (Dixit and Pindyck 1994)

$$
\mu=\alpha+\delta
$$

where $\mu=$ return of the asset; $\alpha=$ growth rate of the value of the asset; and $\delta=$ dividend generated by such asset.

Equating the two expressions above, it is possible to define the following risk-adjusted traffic growth rate:

$$
\alpha^{\text {adjusted }}=r-\delta=\alpha-\beta\left[r_{m}-r\right]
$$

Therefore, there is another stochastic process $\theta_{t}^{\text {adjusted }}$, associated with $\theta_{t}$, such that (Hull 2006)

$$
\frac{d \theta_{t}^{\text {adjusted }}}{\theta_{t}^{\text {adjusted }}}=(r-\delta) d t+\sigma d z
$$

where $\theta_{0}^{\text {adjusted }}=\theta_{0} ; \theta_{t}^{\text {adjusted }}=$ traffic volume, risk adjusted; and $r-\delta=$ new traffic growth rate, risk adjusted.

Starting from this adjusted process, the value of any derivative whose volatility is induced by the underlying variable (traffic) can be determined. This procedure allows to treat the traffic as if it were a financial variable, and then the options-valuation methodology is applied.

The $\beta$ coefficient can be related to the price of traffic risk $(\lambda)$, analogously to a financial asset, through the expression (Dixit and Pindyck 1994)

$$
\lambda=\frac{\mu-r}{\sigma}=\frac{\alpha+\delta-r}{\sigma}
$$

The $\lambda$ parameter of risk must be equal for the traffic and for the project (i.e., for the cash flows obtained by the concessionaire), because the former is the source of uncertainty in the project. Therefore, the following expression is satisfied:

$$
\frac{\mu-r}{\sigma}=\frac{\mu_{\text {project }}-r}{\sigma_{\text {project }}}
$$

where $\mu_{\text {project }}$ and $\sigma_{\text {project }}=$ return and volatility of the project, respectively. Replacing and operating in Eqs. (4), (6), and (7), the following is obtained:

$$
\frac{\beta}{\sigma}=\frac{\beta_{\text {project }}}{\sigma_{\text {project }}} \Rightarrow \beta=\frac{\sigma}{\sigma_{\text {project }}} \beta_{\text {project }}
$$

For the estimation of $\beta$, Lara Galera and Sánchez Soliño (2010) use as a proxy the parameters obtained for the series of the return of the shares of quoted highway concessionaire firms in the Spanish stock market. The values obtained were $\sigma_{\text {project }}=0.22$ and $\beta_{\text {project }}=0.45$. Regarding traffic volatility (defined as the quasistandard deviation of the traffic growth rate), it was calculated that in Spain the annual volatility of traffic in toll motorways tends to average at $7.5 \%$ (Lara Galera 2006). Considering these values in Eq. (8), a characteristic value of $\beta$ equal to 0.15 is obtained. 
The stochastic differential Eq. (5) has a solution of the type

$$
\theta_{t}^{\text {adjusted }}=\theta_{0}^{\text {adjusted }} e^{\left[\left(r-\delta-1 / 2 \sigma^{2}\right) t+\sigma \xi \sqrt{t}\right]}
$$

where $\xi=$ random normal variable $N(0,1)$.

The value of the project $V_{T}$ in any year $T$ is given by

$$
V_{T}=\sum_{i=T}^{N} \mathrm{FCF}_{i}\left(\theta_{i}^{\text {adjusted }}\right) e^{-r(i-T)}
$$

It is assumed that the condition for abandoning the project in year $T(T<N)$, with a value of abandonment $A_{T}$, is that the project is no longer feasible. It can be understood that, for the purpose of modeling, such situation of unfeasibility will be fulfilled when the project value is lower than the outstanding debt of the project, applying the definition of bankruptcy. This criterion can be found in the Spanish legislation on concession contracts (Ministerio de Fomento 2003). Besides, in U.K., the contractor default is considered as the trigger for the early termination of the contract (HM Treasury 2007).

Therefore, the abandonment shall only take place if $V_{T}$ is smaller than $D_{T}$, the latter being the value of the outstanding debt of the project in the year $T$. If the abandonment option is exercised, the concession will perceive the abandonment value $A_{T}$, giving up the residual value of the project, $V_{T}$. The value of the abandonment option on the exercise date will then be given by

$$
P_{T}= \begin{cases}0 & \text { if } V_{T} \geq D_{T} \\ A_{T}-V_{T} & \text { if } V_{T}<D_{T}\end{cases}
$$

and at any given instant $t$ by

$$
P_{t}=e^{-r(T-t)} E\left(P_{T}\right)
$$

where $E=$ expected value operator.

Following the approach outlined above, the decision rule adopted in this paper to determine the exercise of the abandonment option differs from the traditional rule. According to the latter, the abandonment option will be exercised when the value of the project $\left(V_{T}\right)$ at a given time $T$ is less than the value of abandonment $\left(A_{T}\right)$. However, in practice, the abandonment option in concession contracts is only exercised under an insolvency situation leading to the termination of the contract. As has been seen, it was considered that this insolvency occurs when the project value is lower than the outstanding debt. It is normally assumed that the outstanding debt of the project is lower than the abandonment value. Therefore, if $V_{T}<D_{T}$, then $A_{T}-V_{T}$ will always be greater than zero. Otherwise, if the outstanding debt is greater than the abandonment value, then the traditional rule to exercise the option would prevail.

Given that the abandonment option may be exercised at different times, the value of $P_{t}$ can be determined using a Monte Carlo simulation, under the following scheme:

- A trajectory of random values is generated following the outline given by Eq. (9) to determine the traffic $\theta_{t}^{\text {adjusted }}$ for each of the years of the concession.

- In each generated trajectory, the first moment $T$ is observed in which the abandonment option would be exercised. From that moment $T$, the trajectory would be truncated or, alternatively, it would lead to the result that for such traffic trajectory, the option would not be exercised throughout the concession period, according to the criteria defined above, and the value of $A_{T}-$ $V_{T}$ would be calculated.

- The previous two steps are repeated for a significant number of times, counting for each $T$ the number of trajectories where the abandonment option is exercised on that date. In this way, the expected value of the abandonment option for each $T$ can be calculated.

- The risk-free rate $r$ would be used to obtain the total present value of the option at the desired time $t$.

- In addition, it is possible to obtain the value of the likelihood that the abandonment option is exercised at each time during the concession period, as well as the probability that the option is exercised at any time during the life of the concession. To do this, it is necessary to consider that the exercise of the option in a given year is conditional upon not exercising it in any of the previous years.

The procedure described above can be completed by introducing a second source of uncertainty in the modeling, applicable to greenfield motorway concessions. In these kind of projects, in addition to the uncertainty about future traffic evolution, there is also a high uncertainty about the initial traffic. The Monte Carlo simulation procedure described above enables the generation of different traffic trajectories considering the initial traffic as a random variable. This paper considers a normal distribution of the variable consisting of the ratio between the real traffic and the traffic expected by the concessionaire. In addition, it is assumed that future traffic growth is independent of the initial traffic, which is consistent with the traffic behavior as a variable that follows a geometric Brownian motion.

There are several studies that show the empirical evidence available concerning the distribution of the variable $\theta_{0}$ real $/ \theta_{0}$ expected, including those of Flyvbjerg et al. (2005) and Næss et al. (2006). The latter gives a high dispersion of initial real traffic in relation to the expected initial traffic, though it referred to a sample that includes both toll and toll-free motorways. More recently, Bain (2009) provided the results for a large sample of more than 100 projects in various countries, on toll motorways. According to the evidence provided by this study, the relationship between the initial traffic and the expected traffic on toll motorways follows a normal distribution, with an average equal to 0.81 and a standard deviation equal to 0.24 , for countries with a certain tradition in the construction of toll roads. This distribution has been adopted in this work. This would mean that there is a bias in the estimates of initial traffic by concessionaires, who tend to overestimate such traffic to some extent. Furthermore, the dispersion of the distribution of the variable, given by the standard deviation, is high, which shows the difficulty in estimating traffic. Note that, according to the work cited above, the optimistic bias in traffic predictions is considerably higher in countries with little experience in tollmotorways concessions.

\section{Application to a Motorway Concession in Spain}

To illustrate the real-options methodology developed in this paper, the aforementioned procedure will be applied to the case of a greenfield toll-motorway concession in Spain.

A major toll-motorway program was launched in Spain in the late 1990s (Baeza and Vassallo 2010). This program was subject to the general legislation on public infrastructure concessions which established in a specific way how to determine the compensation to the concessionaire upon termination of the concession contract (Ministerio de Fomento 2003). In cases when the concessionaire defaulted, the compensation for the return to the public sector of the asset subject to the concession equals the value of the investment made, minus the corresponding depreciation, minus the indemnity to the public administration for the breach of contract. This latter indemnity (which therefore decreases the value of the compensation to the concessionaire) should be at least equal to 
the guarantee lodged by the concessionaire at the time of the awarding of the contract. The value of this guarantee varies with each contract; a typical value would be $5 \%$ of the investment considered in the contract. This value of $5 \%$ is the minimum guarantee established in the Spanish legislation on public procurement (Jefatura del Estado 2007).

These rules about the termination of concession contracts in the case of the default of the concessionaire represent an important support for the financing of projects. Therefore, they contribute in a decisive way to the attraction of private capital for investment in infrastructure. However, they also represent an implicit cost to the administration, whose scope is determined in this section.

Within the Spanish toll concession program mentioned above, the case of the Airport Axis (M-12) project carried out in Madrid is chosen. This motorway established a new access to terminal T4 of Madrid airport, and it was constructed under a concession agreement.

The construction phase of the project began in 2002 with a concession period of 25 years and an investment of 327.8 million Euros. The traffic expected by the concessionaire at the beginning of the period of operation exceeded an annual average daily traffic of 55,000 vehicles. The financing structure was $25 \%$ of equity and $75 \%$ of debt. Nevertheless, the simulation was made using different levels of debt, to obtain the sensitivity of the option value to this parameter.

The input data used in the valuation were the following:

- Annual growth rate of expected traffic $\alpha=3.5 \%$.

- Annual risk-free rate of return $r=4.63 \%$. The risk-free return is calculated taking as a reference the average interest rates over the past 10 years in the secondary market for 15 -year state bonds in Spain.

- Annual market rate of return $r_{m}=10.45 \%$. The characteristic market return was established by averaging the performance of the stock index IBEX-35 over the last 15 years.

- $\beta=0.15$.

- $\alpha_{\text {adjusted }}=2.63 \%$. This value is obtained from $\alpha_{\text {adjusted }}=\alpha-\beta$ $\left[r_{m}-r\right]=3.5 \%-0.15[10.45-4.63 \%]=2.63 \%$.
- $\delta=2.0 \%$. This value is obtained from $\alpha_{\text {adjusted }}=r-\delta \rightarrow \delta=$ $r-\alpha_{\text {adjusted }}=4.63-2.63 \%=2 \%$.

- Annual volatility of traffic $\sigma=7.5 \%$. This value is the one that was used in this paper as the base case.

In addition, the relationship between the actual initial traffic and the expected initial traffic is characterized, as pointed out in the previous section, as a random variable with distribution $N(0.81$, 0.24), following Bain (2009).

As already mentioned, the existence of the compensation will be modeled as a put option that can be exercised by the concessionaire at certain times. Its possible exercise once every year is considered during the operating period of the concession. In addition, it is also assumed that in practice the option is not exercised during the ramp-up period (that will be set at 3 years), so that all the agents involved in the concession will observe traffic evolution during that period before making a decision.

To set the compensation, in the base case, a value of the indemnity paid to the public administration for the breach equal to $5 \%$ of the initial investment, as mentioned above, was considered. However, the sensitivity of the model to different values of the indemnity was also analyzed. An abandonment option exercised during the operating period is considered for this purpose. Therefore, the case of abandonment of the concession during the construction period is excluded, which would possibly entail a much higher indemnity to the administration.

Taking into account these parameters, and applying the methodology described in the "Abandonment Option in Motorway Concessions" section, the main results obtained are summarized in the following graphs.

As shown in Fig. 1, the value of the abandonment option in the concession in the first exercise date is 19.76 million Euros in the base case. The first exercise date was set by taking into consideration a period of 2 years of construction and then a ramp-up period of 3 years.

As expected, the value of the option decreases in successive dates, as the operating period elapses without the option being exercised. The reason is that in the simulation process the option is exercised, in a given year, if the trajectory of traffic (until this year)

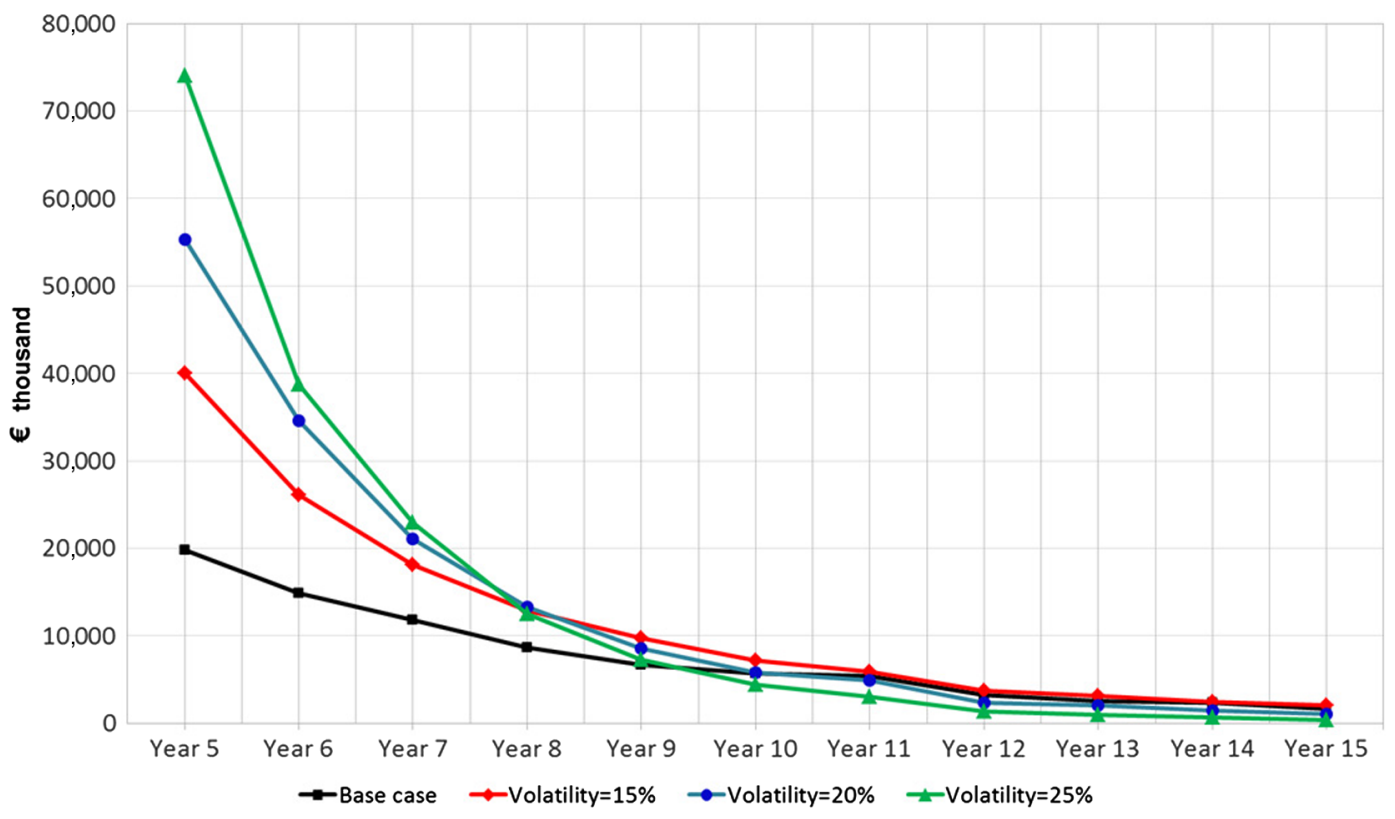

Fig. 1. Value of the abandonment option (thousands of Euros) in each exercise date 


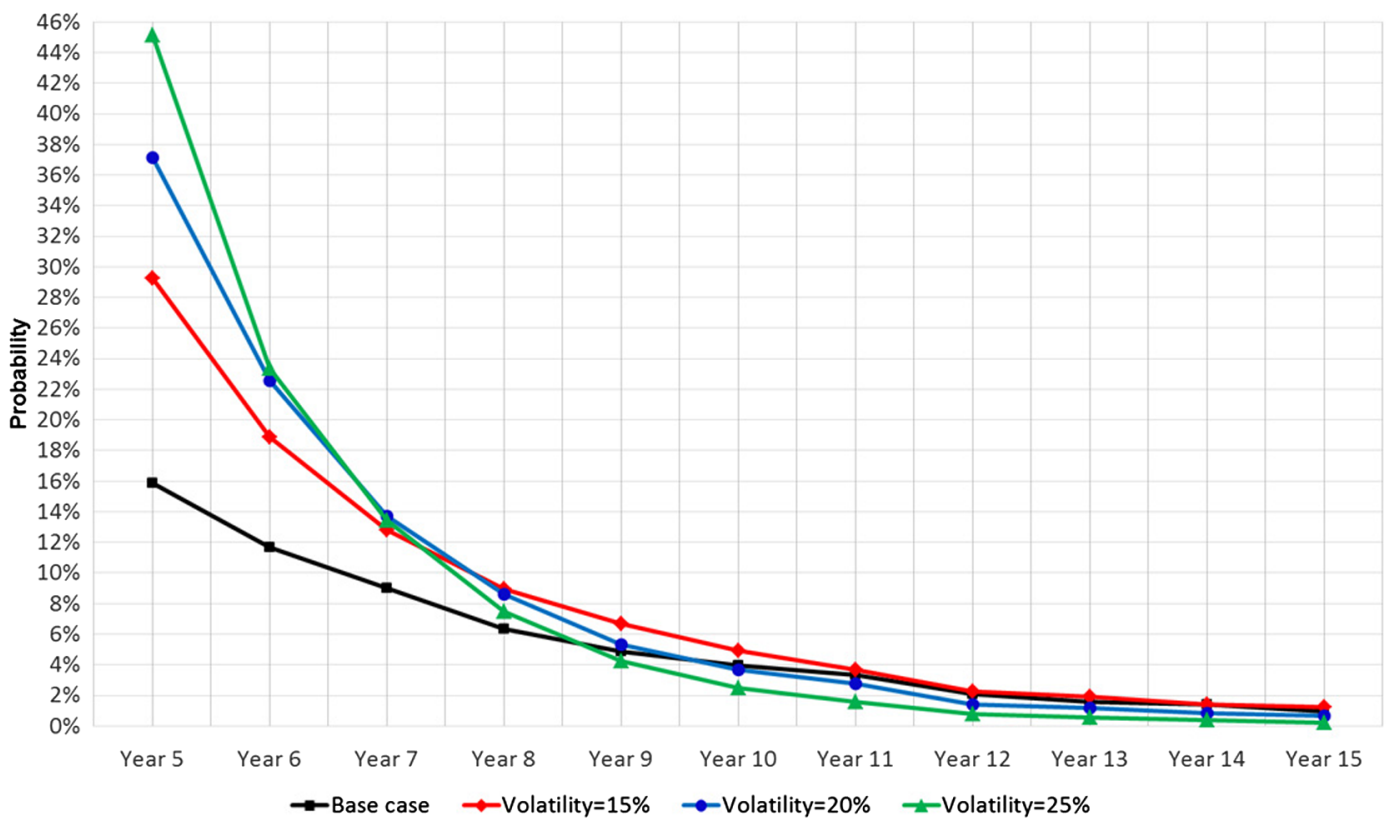

Fig. 2. Probability of exercising the abandonment option each year

is low. Therefore, only trajectories with a high traffic survive, and the probability of exercising the option is lower in subsequent years.

Fig. 1 shows, besides the base case, the results obtained for larger values of traffic volatilities. The sensitivity of the value of the option to the value of this parameter is high, increasing the value of the option as volatility increases.

Additionally, the probabilities of exercising the option are represented in Fig. 2.

As may be observed, in the base case, the probability of exercising the abandonment option is $16 \%$ in the first exercise date, thus decreasing the odds on successive dates. However, increasing traffic volatility increases the likelihood of exercise in the early years.

From these results, the full value of the abandonment option can be obtained by aggregating the results obtained from the different exercise dates of the concession period. These added values, which were calculated at the time of commencement of the concession using the risk-free rate of discount, are given in Fig. 3.

For the base case, the sum of the option values obtained in each year of operation, taken at the beginning of the concession contract and properly discounted, shows a total value of 58.4 million Euros, which represents $17.8 \%$ of the value of the initial investment. Therefore, the total value of the abandonment option represents an important aid from the public administration to the concession. This aid is not quantified in the concession contract, and it is not reflected in the government's budget. However, it is clear that it represents a burden for the public sector and, ultimately, on the taxpayer.

Likewise, the probability of exercising the option at any time during the period of operation can also be obtained by aggregating the probabilities of exercising the option at each exercise date. The results obtained are given in Fig. 4. As shown, the probability of exercising the abandonment option in any of the dates of exercise is $61.01 \%$ in the base case, reaching very high values for higher traffic volatilities.

In Fig. 5, the sensitivity of the total value of the abandonment option to the value of the indemnity paid by the concessionaire to the public administration is shown. As can be observed, the value of the abandonment option decreases significantly when the indemnity is higher. However, the probability of exercising the option

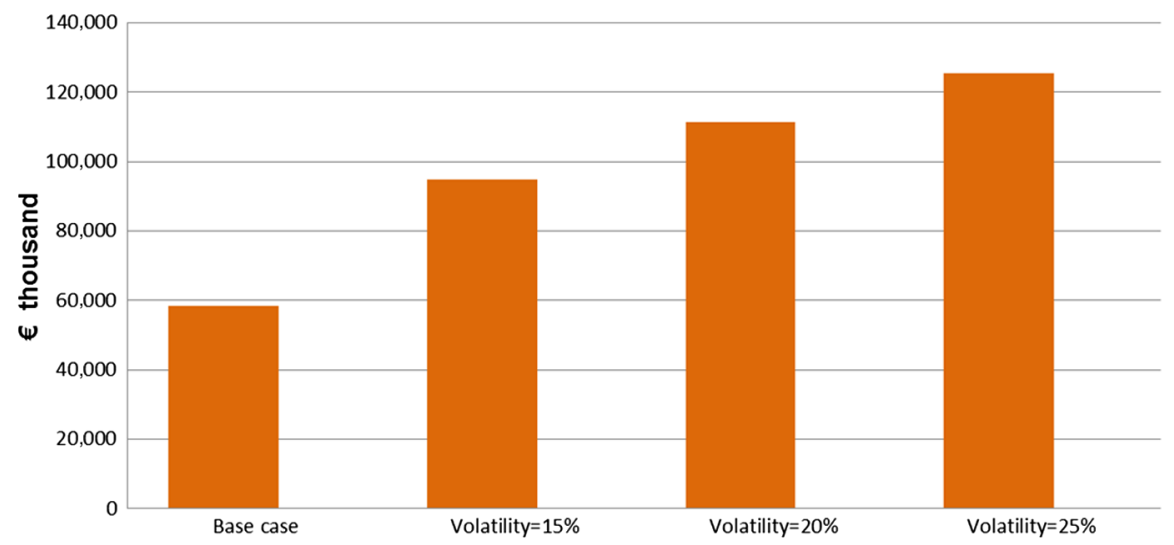

Fig. 3. Total value of the abandonment option at $t=0$ (thousands of Euros) 


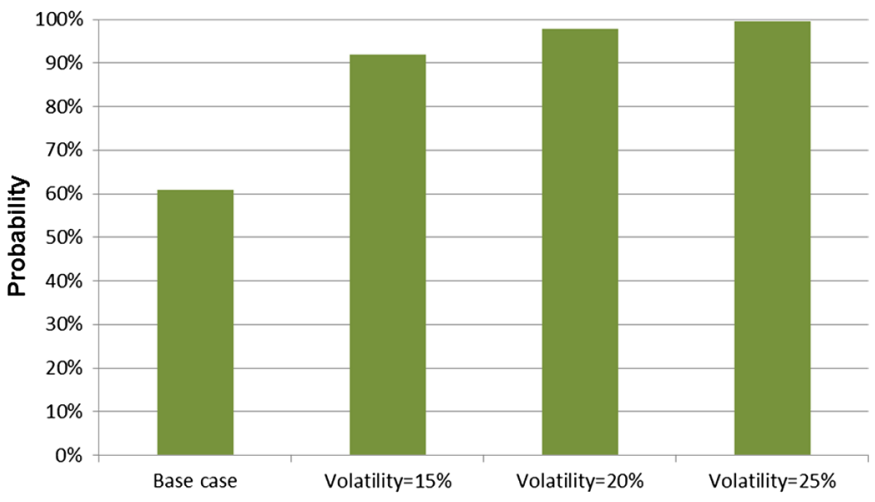

Fig. 4. Probability of exercising the abandonment option sometime during the operating period

at any time during the concession period does not change, because the criterion for exercising the option only considers the value of the project and the outstanding debt.

In addition, different degrees of leverage of the concession were considered. For this purpose, the annual traffic volatility was set at $7.5 \%$, the indemnity paid to the public administration at $5 \%$, and the ratio of debt in relation to total resources of the concession was changed. The aggregated results for the set of all exercise dates are shown in Figs. 6 and 7.

From Figs. 6 and 7, it can be seen that the degree of leverage is a key parameter to determine the value of the abandonment option and, above all, the probability of exercise. It can be seen that the latter increases considerably when the debt of the concession rises. This high sensitivity of the probability of exercising the abandonment option is due to the fact that a high leverage increases the number of random trajectories of traffic for which the value of the concession falls below the level of outstanding debt.

In summary, the results show a significant value of the abandonment option. For the base case analyzed in this paper, the value of the option represents, at the moment of commencement of the concession contract, $17.8 \%$ of the initial investment in the motorway. This amount can be considered as a hidden aid to the concession by the public administration. In this sense, the regulation of insolvency situations in concessions appears to be overly favorable toward the concessionaire in the Spanish legislation. The value of the abandonment option depends on the regulation of the compensation mechanism, and thus the results obtained for the Spanish case cannot be extended to other jurisdictions. Nevertheless, the methodology used for the calculation is applicable to other cases. Even more

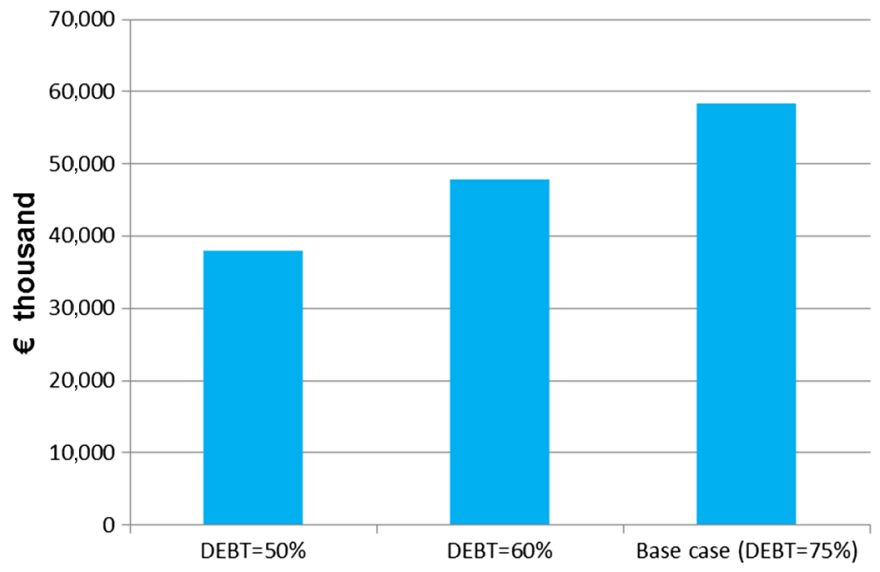

Fig. 6. Total value of the abandonment option (thousands of Euros) at $t=0$, for different degrees of leverage

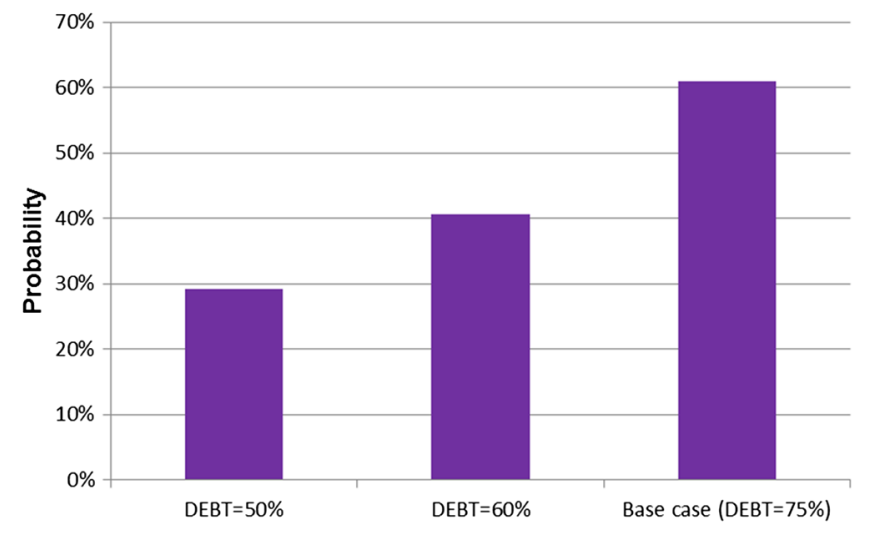

Fig. 7. Probability of exercising the abandonment option at some point during the operation, for different degrees of leverage

significant are the results obtained regarding the probability of exercising the option of abandonment throughout the life of the concession, which for the base case would be above $60 \%$. In other words, this result is equivalent to the probability of the concession becoming unfeasible at some point during the concession period. The parameters adopted to characterize the evolution of traffic volume by no means could be considered extreme. The annual traffic volatility over the life of the concession used in the analysis was $7.5 \%$, which is the average value observed in the Spanish toll roads.

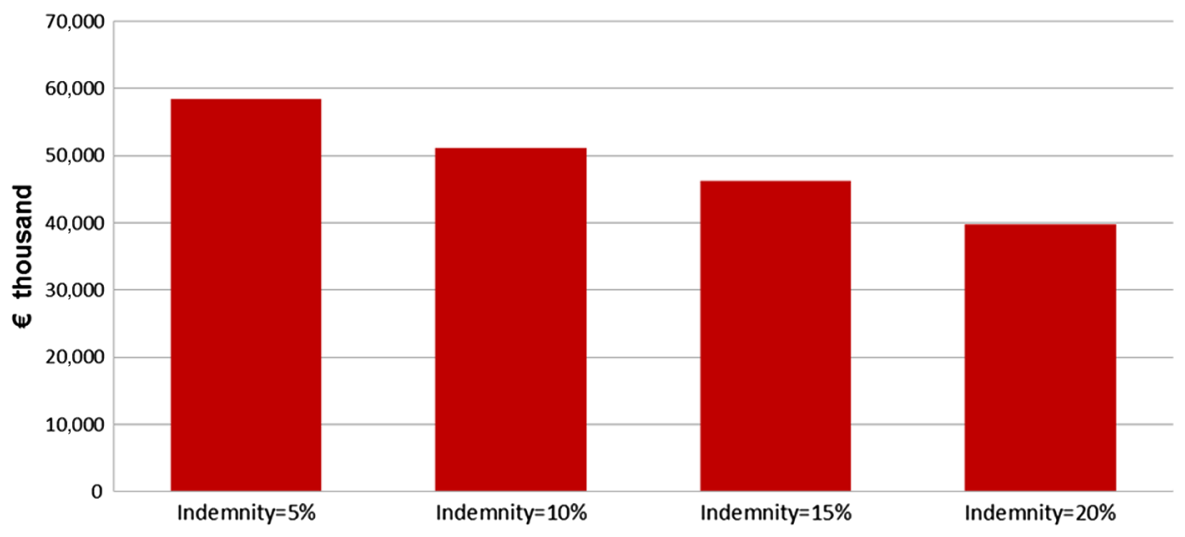

Fig. 5. Total value of the abandonment option (thousands of Euros) at $t=0$, for different values of the indemnity paid to the public administration 
For larger volatilities, both the value of the abandonment option as well as the probability of occurrence are significantly higher.

Regarding the debt structure, one way to reduce the risk of a concession default would be to set a maximum leverage limit. Taking into account the results obtained in this study, debt levels above $50 \%$ of total resources excessively increase the probability of exercising the option of abandonment.

\section{Conclusion}

In motorway concessions, the compensation mechanisms in cases of the concessionaire defaulting can imply a relevant implicit contribution of the public sector to the concession, as presented in this paper. This contribution may be justified to prevent an unfair benefit to the public administration in case of early termination of the concession contract. However, the methodology to appraise the value of this mechanism has not been properly addressed before, which implies a certain lack of transparency in concession contracts.

The main contribution of this paper is to provide a methodology based on the abandonment option, which enables to assess the value of the compensation mechanism at the time of establishing the contract. Logically, the result of the valuation will depend on the specific characteristics of each compensation mechanism, which will be defined in the current legislation or in the concession contract itself.

In this paper, an application to the case of Spanish motorways was developed. In Spain, the treatment of insolvency situations in infrastructure concessions is regulated by legislation. Under Spanish law, the compensation to the concessionaire is determined on the basis of the amount invested reduced by the depreciation of the assets and by the corresponding indemnity to the administration. Based on this approach, the aforementioned methodology was applied to real data from a specific motorway concession. The characteristics of the chosen concession contract are analogous to those of other toll-motorway concessions in Spain, meaning that the results discussed in this paper could potentially be extended to other cases in this country.

The results show that motorway concessions are a highly risky business, due to the inherent characteristics of the underlying asset, the traffic volume. Furthermore, the probability of exercising the option of abandonment, as stated in the model developed in this work, depends only on the residual value of the project and its outstanding debt, factors that are independent from the value of the compensation to the concessionaire, which determines the value of the option, but not the probability of exercise.

The high risk of motorway concession projects should be taken into account in the design of the financing structure of the business; it seems clear that too high leverage ratios were adopted in the past. This result can be generalized for other countries (unlike the results obtained for the value of the abandonment option), because the leverage ratio used in most PPP agreements are even higher than those used in Spanish concessions.

In conclusion, the application of the real-options methodology presented in this paper can contribute to gaining a better understanding of the risks of motorway concessions and promoting a better design of concession contracts, leading to a more reasonable probability of exercising the abandonment option.

Finally, although the model developed in this paper has been specifically applied to motorway concessions, the methodology can be extended to other fields. For example, it can be applied to PPP agreements in public transit, railways, airports, or ports, when the remuneration of the private partner (and therefore, the cash flows of the project) depends on demand. However, the extension of the model is not automatic. In particular, the parameters that characterize the diffusion process followed by the traffic should be studied in each case.

\section{References}

Baeza, M. A., and Vassallo, J. M. (2010). "Private concession contracts for toll roads in Spain: Analysis and recommendations." Public Money Manage., 30(5), 299-304.

Bain, R. (2009). "Error and optimism bias in toll road traffic forecasts." Transportation, 36(5), 469-482.

Black, F., and Scholes, M. (1973). "The pricing of options and corporate liabilities." J. Polit. Econ., 81(3), 637-654.

Brealey, R. A., Myers, S. C., and Allen, F. (2010). Principles of corporate finance, McGraw Hill, New York.

Cabero Colín, F., Sánchez Soliño, A., and Lara Galera, A. L. (2013). "Empirical analysis of traffic volume for the application of the real options theory to motorway concessions." Proc., 13th World Conf. on Transport Research, WCTR Society, Leeds, U.K.

Carpintero, S., and Gómez-Ibañez, J. A. (2011). "Mexico's private toll road program reconsidered." Transp. Policy, 18(6), 848-855.

Chen, A., and Subprasom, K. (2007). "Analysis of regulation and policy of private toll roads in a build-operate-transfer scheme under demand uncertainty." Transp. Res. Part A Policy Pract., 41(6), 537-558.

Chiara, N., Garvin, M. J., and Vecer, J. (2007). "Valuing simple multipleexercise real options in infrastructure projects." J. Infrastruct. Syst., 10.1061/(ASCE)1076-0342(2007)13:2(97), 97-104.

Chow, J. Y. J., and Regan, A. C. (2011). "Network-based real option models." Transp. Res. Part B Method., 45(4), 682-695.

Dixit, A. K., and Pindyck, R. S. (1994). Investment under uncertainty, Princeton University Press, Princeton, NJ.

Flyvbjerg, B., Skamris, M. K., and Buhl, S. L. (2005). "How (in)accurate are demand forecasts in public works projects? The case of transportation." J. Am. Plann. Assoc., 71(2), 131-146.

HM Treasury. (2007). "Standardisation of PFI contracts, version 4." The Stationery Office, London.

Hull, J. C. (2006). Options, futures and other derivatives, 6th Ed., Pearson Prentice-Hall, Upper Saddle River, NJ.

Jefatura del Estado. (2007). Act 30/2007 on public sector contracts, Boletín Oficial del Estado, Madrid, Spain.

Kester, W. C. (1984). “Today's options for tomorrow's growth.” Harvard Bus. Rev., 62(2), 153-160.

Lara Galera, A. L. (2006). "Desarrollo de un modelo de valoración de concesiones de autopistas basado en la teoría de opciones reales. Validación mediante el análisis de series históricas de datos de concesiones en servicio. [A model for the valuation of highway concessions based on the real options theory. Calibration of the model starting from historical data]." Ph.D. thesis, E.T.S.I. Caminos Canales y Puertos, Univ. Politécnica de Madrid, Madrid, Spain (in Spanish).

Lara Galera, A. L., and Sánchez Soliño, A. (2010). "A real options approach for the valuation of highway concessions." Transp. Sci., 44(3), 416-427.

Margrabe, W. (1978). "The value of an option to exchange one asset for another." J. Finance, 33(1), 177-186.

Merton, R. C. (1973). "Theory of rational option pricing." Bell J. Econ. Manag. Sci., 4(1), 141-183.

Ministerio de Fomento. (2003). Act to regulate the public works concession contract, Madrid, Spain.

Mun, J. (2002). Real options analysis: Tools and techniques for valuing strategic investments and decisions, Wiley, Hoboken, NJ.

Myers, S. C., and Majd, S. (1990). "Abandonment value and project life." Advances in futures and options research, Vol. 4, JAI Press, Greenwich, CT, 1-12.

Næss, P., Flyvbjerg, B., and Buhl, S. (2006). "Do road planners produce more 'honest numbers' than rail planners? An analysis of accuracy in road-traffic forecasts in cities versus peripheral regions." Transp. Rev., 26(5), 537-555.

National Audit Office. (2009). "The failure of Metronet." Rep. of Comptroller and Auditor General, The Stationery Office, London. 
Porter, M. (1987). "From competitive advantage to corporate strategy." Harvard Bus. Rev., 65(3), 43-59.

Robichek, A. A., and Van Horne, J. C. (1967). "Abandonment value and capital budgeting." J. Finance, 22(4), 577-590.

Sánchez Soliño, A., and Lara Galera, A. L. (2012). "Unit root analysis of traffic time series in toll highways." J. Civ. Eng. Archit., 6(12), 1641-1647.
Sharpe, W. F. (1964). "Capital asset prices: A theory of market equilibrium under conditions of risk." J. Finance, 19(3), 425-442.

Zhao, T., Sundararajan, S. K., and Tsen, C. (2004). 